\title{
Choriogonadotropin Adjusted for Maternal Weight Measurement
}

National Cancer Institute

\section{Source}

National Cancer Institute. Choriogonadotropin Adjusted for Maternal Weight

Measurement. NCI Thesaurus. Code C161374.

The determination of the amount of choriogonadotropin, adjusted for maternal weight, present in a sample. 